\title{
Clinical Reasoning: A young healthy woman with difficult-to-wean acute ventilator dependence
}

Swathy Chandrashekhar, MD, and Eduardo A. De Sousa, MD

Neurolog ${ }^{\circledR}$ 2020;94:e1340-e1343. doi:10.1212/WNL.0000000000009150
Correspondence

Dr. Chandrashekhar

swathy.chandrashekhar@

gmail.com

\section{Section 1}

A 25-year-old woman with a history of occipital headaches and chronic smoking (2 pack-years) was found unconscious at home following a week of fatigue and drowsiness. She was intubated on-scene and admitted to the medical intensive care unit (ICU) for hypercapnic respiratory failure. CT scan of the chest revealed bibasilar opacities, leading to empiric treatment of pneumonia despite absence of fever and cough. Pulmonary opacities and mental status improved with treatment, but the patient failed multiple attempts to wean from ventilation before ultimate extubation. The patient then experienced sleep apnea as witnessed by hospital staff and remained persistently hypercapnic, requiring biphasic positive airway pressure (BiPAP) support. Bedside ultrasound revealed severe bidiaphragmatic weakness, prompting neurologic consultation for apparent neuromuscular respiratory failure. On examination, cranial nerves were intact. The patient had normal muscle tone, $4 / 5$ strength in the right deltoid and right intrinsic hand muscles, no fatigable oculobulbar weakness, diffuse hyperreflexia (3/4 in bilateral brachioradialis, biceps, and triceps, $4 / 4$ in both patellars, with 5-6 beats of clonus in both ankles), and bilateral Babinski sign. The patient had no cerebellar signs.

\section{Questions for consideration:}

1. Where should the lesion be localized?

2. What is the differential diagnosis of neuromuscular respiratory failure?

GO TO SECTION 2 


\section{Section 2}

Lesions in neuromuscular disorders that can affect respiratory function can be localized to the cervicomedullary junction, anterior horn cells of the cervicothoracic cord, multiple nerve roots, the brachial plexus, the bilateral phrenic nerves, peripheral nerves, the neuromuscular junction, or muscle.

The patient's signs (bilateral diaphragmatic weakness, possible central apnea, diffuse hyperreflexia, and weakness in the right $\mathrm{C} 5, \mathrm{C} 8$, and $\mathrm{T} 1$ myotomes) are concerning for a longsegment cervicomedullary junction lesion.

Intramedullary lesions of the craniocervical junction would have to be longstanding (slowly progressive or static) given the paucity of signs on examination compared to the expected extent of structural involvement (i.e., medulla to T1). Syringomyelia, neoplasms, and spinal arteriovenous malformations are top considerations.

Of the anterior horn cell diseases, amyotrophic lateral sclerosis is most common. Asymmetric limb or bulbar-onset weakness progressing in a regional fashion is typical and on examination reveals mixed upper (hyperreflexia as above) and lower (such as atrophy or fasciculations; absent in this patient) motor neuron signs. Polio-like syndrome secondary to certain viruses is characterized by acute flaccid paralysis of one or more limbs, possibly with pharyngeal or diaphragmatic involvement, during an acute febrile illness (unlike this case). For this lower motor neuron syndrome, hyporeflexia is expected. Respiratory failure in spinal muscular atrophy and Kennedy disease (X-linked spinobulbar muscular atrophy) is usually proportional to the degree of generalized weakness and is seen in patients with bulbar dysfunction. These diseases are associated with hyporeflexia and the latter with gynecomastia, testicular atrophy, and infertility. ${ }^{1}$

At the nerve root level, polyradiculopathy (acute in GuillainBarré syndrome, chronic in chronic inflammatory demyelinating polyradiculoneuropathy, or other variants) can also result in diaphragmatic paresis. Importantly, these syndromes are associated with hyporeflexia or areflexia (rather than hyperreflexia as in this case), and respiratory failure is usually due to disease progression from typical initial symmetric sensorimotor symptoms in the extremities to eventually involve pharyngeal and respiratory muscles. ${ }^{1}$

Brachial plexitis (i.e., neuralgic amyotrophy or ParsonageTurner syndrome) follows, which can reportedly cause bidiaphragmatic weakness. The characteristic clinical course begins with acute severe pain in the scapulohumeral region followed by progressive weakness, atrophy, and sensory loss in the arm and shoulder; diaphragmatic involvement is not uncommon. A variant with isolated phrenic neuropathy has been described. ${ }^{2}$

Distal to the plexus, bilateral phrenic neuropathies may occur with vasculitis, diabetes mellitus, chronic meningitides, and sarcoidosis, as part of multifocal motor neuropathy, ${ }^{3}$ or in association with critical illness polyneuropathy (CIP). Clinical context and temporal progression of symptoms can distinguish these etiologies.

Neuromuscular junction disorders (myasthenia gravis [MG], Lambert-Eaton myasthenic syndrome [LEMS], and botulism) are frequent suspects in such scenarios. MG classically features fatigable weakness, often presenting with ocular symptoms, and respiratory dysfunction occurring in patients with generalized myasthenia or prominent bulbar disease. LEMS is typically associated with areflexia and dysautonomia and is often paraneoplastic.

Muscle pathologies like dystrophinopathies, myotonic dystrophies, or myositis, or congenital, metabolic, or mitochondrial myopathies, can be associated with respiratory failure; again, respiratory muscle weakness is proportional to the degree of generalized weakness. Involvement of other organ systems (i.e., cardiac, smooth muscle, ocular) is expected. ${ }^{1}$ Adult-onset Pompe disease (acid maltase deficiency) presents as a proximal myopathy, similarly to a limb-girdle muscular dystrophy but with a preponderance towards the diaphragm and respiratory muscles. Electrographic myotonia in the paraspinals without clinical myotonia is a helpful distinguishing clue.

Neuromuscular weakness in the ICU with failure to wean from mechanical ventilation may be due to critical illness myopathy, CIP, or a combination thereof, occurring within 1-2 weeks of admission to the ICU. Depending on the degree of overlap, flaccid quadriparesis with atrophy, peripheral sensory loss, or hyporeflexia can exist. Cranial nerves are usually spared. Common triggers are sepsis, hyperglycemia, multiorgan failure, mechanical ventilation, and exposure to neuromuscular blocking agents or glucocorticoids. ${ }^{4}$

\section{Question for consideration:}

1. Which investigations narrow the differential?

GO TO SECTION 3 


\section{Section 3}

The first priority is to evaluate cardiorespiratory etiologies for acute respiratory failure. If a neuromuscular etiology is suspected, a thorough history and examination is vital to localize the lesion. For signs predominant in upper motor neuron pathologies, brain and $\mathrm{C}$-spine imaging are prioritized. A lower motor neuron pathology, depending on localization, could entail antibody testing, serologies, CSF studies, or EMG.

Cardiopulmonary workup of the patient was unremarkable. CT of the head on admission showed tonsillar ectopia but no hydrocephalus, mass lesions, or cerebral edema. Bidiaphragmatic paresis seen on bedside ultrasound was confirmed using a fluoroscopic sniff test. An empiric pyridostigmine trial minimally improved symptoms. Antibodies for myasthenia were negative.

Upon neurologic consultation for possible neuromuscular respiratory failure and central hypopnea, based on the discovery of florid hyperreflexia, an MRI of the brain was obtained, revealing a significant tonsillar ectopia of $18 \mathrm{~mm}$ below the foramen magnum and a dorsal cervicomedullary bump concerning for Chiari I malformation. Dedicated spine MRIs then captured an extensive C2-T6 syrinx (figure). Pulmonary function tests demonstrated restrictive disease pattern. Polysomnography revealed severe obstructive sleep apnea with an apnea-hypopnea index of 51. Due to this mixed pattern and her preference for nonsurgical management, the patient was discharged with nocturnal BiPAP support. At follow-up, her respiratory status remained stable, but she had worsening right hemiparesis with sensory ataxia and required a walker for ambulation. She is now reconsidering surgical options.

\section{Questions for consideration:}

1. What are the pathophysiologic mechanisms of respiratory failure in this case?

2. What are the considerations in the management of Chiari malformation-related sleep-disordered breathing?

Figure Brain and spine MRI
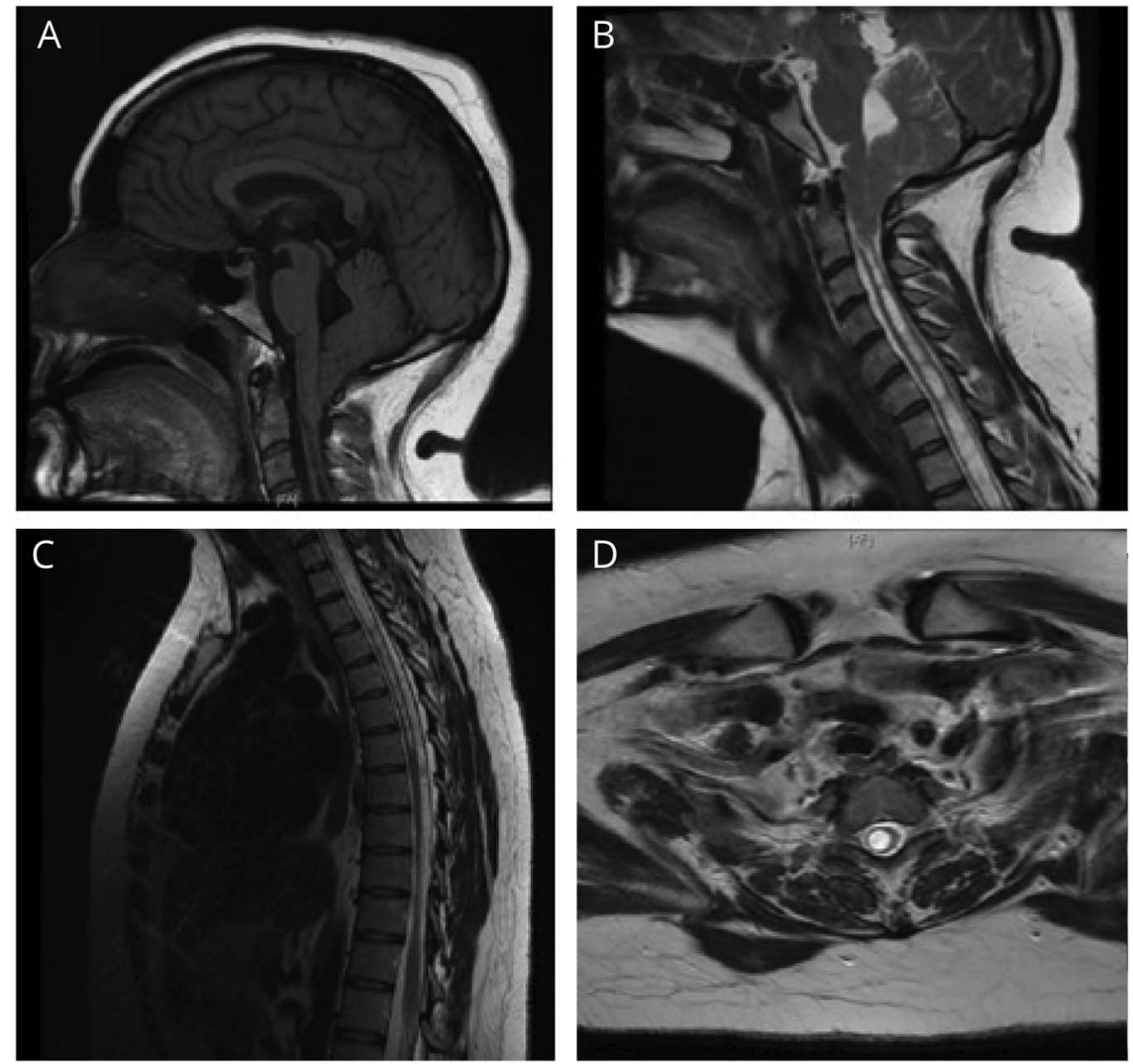

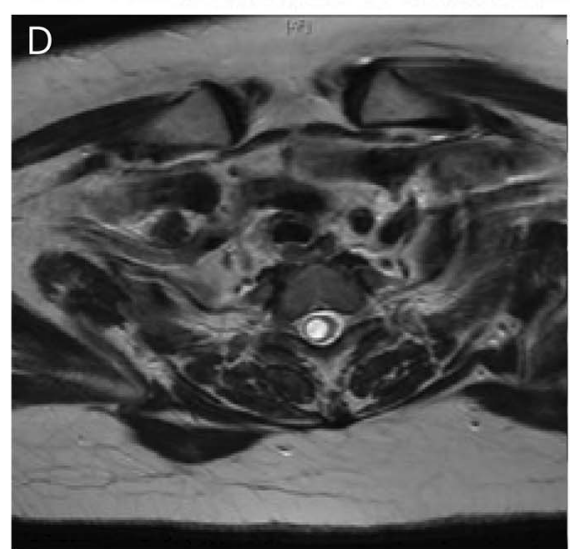

(A) Sagittal T1 image from MRI of the brain demonstrates an 18-mm tonsillar ectopia, dorsal cervicomedullary bump, and syringomyelia concerning for Chiari I malformation. (B) Sagittal T2 view from MRI of the cervical spine demonstrates large intrathecal hyperintensity consistent with a syrinx, extending downward from the C2 level. The lower limit was not captured in the image. (C) Sagittal T2 view from MRI of the thoracic spine demonstrates large intrathecal hyperintensity consistent with a syrinx and extending up to the T6 level. (D) Axial T2 view of the cervical spine shows a markedly dilated central canal appearing as a prominent intrathecal hyperintensity, consistent with syringomyelia. 


\section{Section 4}

Respiratory failure in patients with Chiari malformations can be central, obstructive, or mixed. ${ }^{5}$ Dysfunction in central respiratory events is believed to result from compression of central respiratory centers, compression of cranial nerves IX and X, or changes in afferent nerves due to expansion of syringomyelia. The latter is illustrated by patients who may be asymptomatic until a minor respiratory infection quickly progresses to respiratory failure; this scenario may be due to dysfunctional afferents from peripheral chemoreceptors, preventing an appropriate respiratory center response to infection-related hypoxia. Obstructive respiratory changes may appear in the context of cranial nerve dysfunction (nerves IX, X, XI, and XII) due to compression that would facilitate upper airway collapse.

With Chiari I malformations, respiratory depression can occur as a postoperative complication. Respiratory failure due to Chiari I malformation with or without syringomyelia is rare but has been reported. ${ }^{6}$ Fish et al. ${ }^{7}$ reported 2 patients with Chiari I malformations without syringomyelia who had brainstem compression-related central hypoventilation. Bullock et al. ${ }^{8}$ reported 2 patients with Chiari I malformations and syringomyelia who originally presented with acute respiratory failure; both had diaphragm dysfunction on radiography, and respiration improved following posterior fossa decompression.

Chiari-associated respiratory failure presents in several variations. It is important to distinguish the type of apneas (e.g., using polysomnography) in each patient to customize treatment.

Ferré Masó et al. ${ }^{9}$ reviewed sleep disorders in patients with Chiari I malformations and inferred the following approach based on 22 prior studies regarding response to surgical intervention. Posterior fossa decompression mainly improves central respiratory parameters, but results for the effect on obstructive apnea have been mixed (no change, partial improvement, or complete resolution). It was thus proposed that patients with predominantly obstructive apnea may be conservatively managed with noninvasive positive pressure ventilation, but those with central hypoventilation would require posterior fossa decompression.

Recurrent respiratory failure despite surgical decompression has been reported between 2 and 5 years posttreatment; patients must be followed with a high index of suspicion for recurrence. Repeating polysomnography when indicated is beneficial, and some argue that this could detect subclinical sleep-disordered breathing, allowing for early intervention to prevent associated mortality and morbidity. ${ }^{10}$
Chiari I malformation is a treatable condition that must be considered in the diagnostic evaluation of unexplained respiratory failure in a relatively healthy patient. Conversely, routine pulmonary function tests should be considered in these patients given the risk of progressive worsening or sudden deterioration of respiratory function and death.

\section{Acknowledgment}

The authors thank Omer Suhaib, MD, INTEGRIS Neurology at Baptist Medical Center, Oklahoma City, for manuscript review; and Jennifer Dennis-Wall, $\mathrm{PhD}$, Owner, Sensical Science LLC, for editing the manuscript for nonintellectual content.

\section{Study funding}

No targeted funding reported.

\section{Disclosure}

The authors report no disclosures relevant to the manuscript. Go to Neurology.org/ $\mathrm{N}$ for full disclosures.

\section{Appendix Authors}

\begin{tabular}{lll}
\hline Name & Location & Contribution \\
\hline $\begin{array}{l}\text { Swathy } \\
\text { Chandrashekhar, } \\
\text { MD }\end{array}$ & $\begin{array}{l}\text { University of } \\
\text { Oklahoma Health } \\
\text { Sciences Center, } \\
\text { Oklahoma City }\end{array}$ & $\begin{array}{l}\text { Designed and } \\
\text { conceptualized study, } \\
\text { analyzed the data, } \\
\text { drafted the manuscript } \\
\text { for intellectual content }\end{array}$ \\
\hline $\begin{array}{l}\text { Eduardo A. De } \\
\text { Sousa, MD }\end{array}$ & Mercy Clinic & $\begin{array}{l}\text { Interpreted the data, } \\
\text { revised the manuscript } \\
\text { for intellectual content }\end{array}$ \\
\hline
\end{tabular}

\section{References}

1. Gilchrist JM. Overview of neuromuscular disorders affecting respiratory function. Semin Respir Crit Care Med 2002;23:191-200.

2. Nardone R, Bernhart H, Pozzera A, Taddei M, Tezzon F. Respiratory weakness in neuralgic amyotrophy: report of two cases with phrenic nerve involvement. Neurol Sci 2000;21:177-181.

3. Boonyapisit K, Katirji B. Multifocal motor neuropathy presenting with respiratory failure. Muscle Nerve 2000;23:1887-1890.

4. Latronico N, Bolton CF. Critical illness polyneuropathy and myopathy: a major cause of muscle weakness and paralysis. Lancet Neurol 2011;10:931-941.

5. Dauvilliers Y, Stal V, Abril B, et al. Chiari malformation and sleep related breathing disorders. J Neurol Neurosurg Psychiatry 2007;78:1344-1348.

6. Alvarez D, Requena I, Arias M, Valdés L, Pereiro I, De la Torre R. Acute respiratory failure as the first sign of Arnold-Chiari malformation associated with syringomyelia. Eur Respir J 1995;8:661-663.

7. Fish DR, Howard RS, Wiles CM, Simon L. Respiratory arrest: a complication of cerebellar ectopia in adults. J Neurol Neurosurg Psychiatry 1988;51: 714-716.

8. Bullock R, Todd NV, Easton J, Hadley D. Isolated central respiratory failure due to syringomyelia and Arnold-Chiari malformation. BMJ 1988;297:1448-1449.

9. Ferré Masó A, Poca MA, de la Calzada MD, Solana E, Romero Tomás O, Sahuquillo J. Sleep disturbance: a forgotten syndrome in patients with Chiari I malformation. Neurologia 2014;29:294-304.

10. Zolty P, Sanders MH, Pollack IF. Chiari malformation and sleep-disordered breathing: a review of diagnostic and management issues. Sleep 2000;23:637-643. 


\section{Neurology}

\section{Clinical Reasoning: A young healthy woman with difficult-to-wean acute ventilator dependence}

Swathy Chandrashekhar and Eduardo A. De Sousa

Neurology 2020;94;e1340-e1343 Published Online before print February 28, 2020

DOI 10.1212/WNL.0000000000009150

This information is current as of February 28, 2020

\section{Updated Information \&} Services

References

Subspecialty Collections

Permissions \& Licensing

Reprints including high resolution figures, can be found at: http://n.neurology.org/content/94/12/e1340.full

This article cites 10 articles, 4 of which you can access for free at: http://n.neurology.org/content/94/12/e1340.full\#ref-list-1

This article, along with others on similar topics, appears in the following collection(s):

All Clinical Neurology

http://n.neurology.org/cgi/collection/all_clinical_neurology All Neuromuscular Disease

http://n.neurology.org/cgi/collection/all_neuromuscular_disease Sleep apnea

http://n.neurology.org/cgi/collection/sleep_apnea

Information about reproducing this article in parts (figures,tables) or in its entirety can be found online at:

http://www.neurology.org/about/about_the_journal\#permissions

Information about ordering reprints can be found online:

http://n.neurology.org/subscribers/advertise

Neurology ${ }^{\circledR}$ is the official journal of the American Academy of Neurology. Published continuously since 1951, it is now a weekly with 48 issues per year. Copyright () 2020 American Academy of Neurology. All rights reserved. Print ISSN: 0028-3878. Online ISSN: 1526-632X.

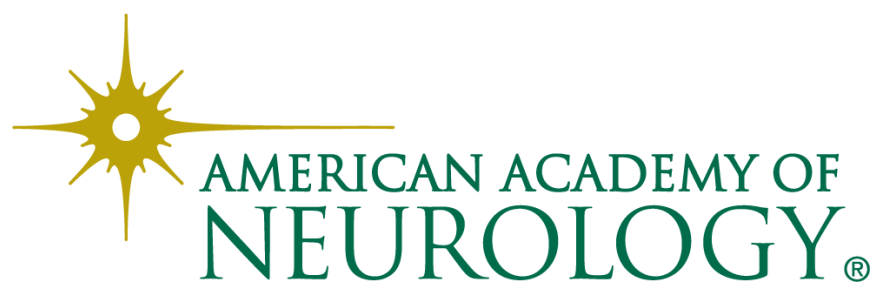

